\title{
Survival and prognostic factors of non-small cell lung cancer patients with postoperative locoregional recurrence treated with radical radiotherapy
}

\author{
Li Ma ${ }^{\dagger}$, Bo Qiu ${ }^{\dagger}$, Jun Zhang, Qi-Wen Li, Bin Wang, Xu-Hui Zhang, Meng-Yun Qiang, Zhao-Lin Chen,
} Su-Ping Guo* and Hui Liu*

\begin{abstract}
Background: Locoregional recurrence remains the challenge for long-term survival of non-small cell lung cancer (NSCLC) patients after radical surgery, and curative-intent radiotherapy could be a treatment choice. This study aimed to assess the survival and prognostic factors of patients with postoperative locoregionally recurrent NSCLC treated with radical radiotherapy.

Methods: We reviewed medical records of 74 NSCLC patients with postoperative locoregional recurrence who received radical radiotherapy between April 2012 and February 2016 at Sun Yat-sen University Cancer Center (Guangzhou, China). The efficacy and safety of radical radiotherapy were analyzed. The probability of survival was estimated using the Kaplan-Meier method and compared using the log-rank test. The Cox proportional hazards model was used to identify prognostic factors.

Results: Grade 3/4 adverse events included neutropenia (8 cases, 10.8\%), esophagitis (7 cases, 9.5\%), pneumonitis (1 case, 1.4\%), and vomiting (1 case, 1.4\%). The 2-year overall survival, progression-free survival, local recurrencefree survival (LRFS), and distant metastasis-free survival (DMFS) rates of all patients were 84.2, 42.5, 70.0, and 50.9\%, respectively. Univariate and multivariate analyses showed that a higher biological effective dose (BED) of radiation was associated with longer LRFS [hazard ratios $(\mathrm{HR})=0.317,95 \%$ confidence interval $(\mathrm{Cl})=0.112-0.899, P=0.016$ ] and that wild-type epidermal growth factor receptor (EGFR) was associated with longer DMFS compared with EGFR mutation ( $\mathrm{HR}=0.383,95 \% \mathrm{Cl}=0.171-0.855, P=0.019)$.
\end{abstract}

Conclusions: Radical radiotherapy is effective and well-tolerated in NSCLC patients with postoperative locoregional recurrence. High BED is a predictor for long LRFS, and the presence of wild-type EGFR is a predictor for long DMFS.

Keywords: Non-small cell lung cancer, Locoregional recurrence, Radical radiotherapy, Biological effective dose, Epidermal growth factor receptor

\footnotetext{
*Correspondence: guosp@sysucc.org.cn; liuhuisysucc@sina.com 'Li Ma and Bo Qiu contributed equally to this work Department of Radiation Oncology, Sun Yat-sen University Cancer Center, State Key Laboratory of Oncology in South China, Collaborative Innovation Center for Cancer Medicine, 651 Dongfeng Road East, Guangzhou, Guangdong 510060, P. R. China
} provided you give appropriate credit to the original author(s) and the source, provide a link to the Creative Commons license, and indicate if changes were made. The Creative Commons Public Domain Dedication waiver (http://creativecommons.org/ publicdomain/zero/1.0/) applies to the data made available in this article, unless otherwise stated. 


\section{Introduction}

Lung cancer remains the most common cancer and the first leading cause of cancer-related death worldwide [1]. For patients with early-stage (stages I and II) and resectable stage III. A non-small cell lung cancer (NSCLC), the National Comprehensive Cancer Network (NCCN) guidelines recommend surgical resection to be the primary treatment as it offers a chance of cure. The 5-year overall survival (OS) rates of patients who had undergone complete tumor resection range from 24 to $73 \%[2,3]$, and postoperative recurrence remains the challenge for long-term survival. The recurrence rates of patients who have undergone surgery range from 34 to $45 \%$ [4-7]. Patterns of failure include distant metastasis, locoregional recurrence, and distant metastasis with locoregional recurrence [8]. Locoregional recurrence occurs in $20-45 \%$ patients $[5,9-11]$.

Unlike the patients with distant failure, the patients with locoregional recurrence after radical surgery without hematogenous spreading can be cured by sufficient local treatment [12]. Most patients with locoregionally recurrent disease cannot bear secondary radical surgery, which highlights the importance of radiotherapy for curative purpose. In the previous studies, radiotherapy has been reported to achieve a promising outcome in patients with locoregionally recurrent NSCLC, with a median OS of 17 to 37.3 months [12-16]. However, most of these studies had small sample sizes. In clinical practice, the standard treatment has not been established regarding the radiation dose or whether in combination with chemotherapy. Moreover, the prognostic factors and failure patterns after radical radiotherapy are also worthy of exploration. In the present study, we evaluated the survival, prognostic factors, and failure patterns after radical radiotherapy for patients with postoperative locoregional recurrence of NSCLC.

\section{Patients and methods}

\section{Patient selection and acquisition of clinical data}

NSCLC patients with postoperative locoregional recurrence treated with radical radiotherapy with or without concurrent chemotherapy between April 2012 and February 2016 at Sun Yat-sen University Cancer Center (Guangzhou, China) were screened. Patient selection criteria were as follows: (1) R0 resection (no residual microscopic disease) for primary NSCLC; (2) postoperative recurrence proved by biopsy or confirmed by imaging modalities and subsequent clinical outcomes; (3) recurrent disease within the ipsilateral hemithorax, mediastinum, and/or supraclavicular fossa; and (4) no metastases to solid organs, the pleura, or the peritoneum. Patients who had previous or recent another malignancy or
Eastern Cooperative Oncology Group (ECOG) performance status $>2$ were excluded.

Clinical data collected from each patient included age, sex, thoracic surgery history, stage and histology of primary NSCLC, epidermal growth factor receptor (EGFR) mutation status, interval between surgery and recurrence, and recurrence sites. The 7th edition of the American Joint Committee on Cancer (AJCC) staging system for lung cancer was used to stage the primary tumor.

\section{Ethical statement}

The treatment of all patients was discussed by the thoracic multi-disciplinary treatment team, and participant information collection was approved by the Ethics Committee of Sun Yat-sen University Cancer Center. Written informed consent was obtained from patients for the use of their data in clinical research.

\section{Radical radiotherapy}

Patient immobilization, simulation, and treatment planning were performed according to the standard protocol of radiotherapy for lung cancer in Sun Yat-sen University Cancer Center [17]. With the patient in the supine position, a cradle for immobilization was made with vacuum. Using 4-dimensional computed tomography (4D-CT), 3-dimensional (3D) data sets associated with 10 respiratory phases in $0.5-\mathrm{cm}$ thickness slices were constructed, and a maximum intensity projection data set was generated. All 11 data sets were exported to the Monaco planning system (Elekta Medical Systems, Stockholm, Sweden) for target contouring and treatment planning. Individual patient was scanned from the atlas (C1) level to the second lumbar vertebra (L2) level to cover the whole neck and lungs. Briefly, the gross tumor volume (GTV-lung plus GTV-lymph node) consisted of recurrent lesion diagnosed by biopsy or subsequent CT scan; the regions of tumor revealed by endoscopy but not seen on CT images were also included in the GTV-lung. The clinical target volume (CTV) comprised a $0.6-\mathrm{cm}$ margin around GTV-lung and selected lymph node region. CTV was not necessary for stereotactic body radiotherapy (SBRT). Two planning target volume (PTV) had been defined: PTV1 was defined as the GTV plus a 0.6$\mathrm{cm}$ margin, and PTV2 was defined as the CTV plus a 0.6- $\mathrm{cm}$ margin in all directions. The intensity-modulated radiotherapy (IMRT) or 3-dimensional conventional radiotherapy (3D-CRT) technique was used to deliver a median dose of 60 Gy (range 56-68 Gy) to PTV1, and 46 Gy (range 40-54 Gy) to PTV2 in a median of 26 fractions (range 15-35 fractions). SBRT was performed to deliver a median dose of 50 Gy (range 50-70 Gy) in a median of 10 fractions (range 10-12 fractions). 


\section{Concurrent chemotherapy}

The regimens of concurrent chemotherapy mostly included platinum-based dual drugs: (1) weekly paclitaxel/docetaxel $\left(25 \mathrm{mg} / \mathrm{m}^{2}\right)$ and cisplatin/nedaplatin $\left(25 \mathrm{mg} / \mathrm{m}^{2}\right)$; and (2) pemetrexed $\left(500 \mathrm{mg} / \mathrm{m}^{2}\right)$ and cisplatin/nedaplatin $\left(75 \mathrm{mg} / \mathrm{m}^{2}\right)$ every 3 weeks. Singleagent treatment included pemetrexed $\left(500 \mathrm{mg} / \mathrm{m}^{2}\right)$, taxel $\left(175 \mathrm{mg} / \mathrm{m}^{2}\right)$, and 5-fluorouracil $\left(2.75 \mathrm{~g} / \mathrm{m}^{2}\right)$ every 3 weeks.

\section{Follow-up}

The follow-up started since the first day of radiotherapy and ended on May 31, 2017. Tumor response was assessed 2 months after radical radiotherapy according to the Response Evaluation Criteria In Solid Tumors (RECIST). The responses included complete response $(\mathrm{CR})$, partial response (PR), progressive disease (PD), and stable disease (SD). The adverse events were graded according to the Common Toxicity Criteria for Adverse Events version 4.0 (CTCAE 4.0) from the start of radiotherapy until 1 year afterward. Patients underwent chest and upper abdominal CT scan every 3 months and brain magnetic resonance imaging (MRI) every 6 months for the first 2 years; chest and upper abdominal CT and brain MRI every 6 months for another 3 years, and then annually. Whole-body bone scan was performed when patients were suspected for bone metastasis.

Locoregional recurrence was defined as disease recurrence at the surgical margin, ipsilateral hemithorax, or regional lymph nodes. Metastasis to the contralateral lung and to outside of the hemithorax or mediastinum was defined as distant metastasis. OS was defined as the duration from the first day of radical radiotherapy to the date of death from any cause or to the last visit before May 31, 2017. Patients were censored at the date of last follow-up if alive or lost to follow-up. Progression-free survival (PFS), locoregional recurrence-free survival (LRFS), and distant metastasis-free survival (DMFS) were defined as the interval from the first day of radical radiotherapy to documented disease progression, locoregional recurrence, and distant metastasis, respectively. Patients were censored at the date of death or the date of last follow-up with no evidence of indicated events.

\section{Statistical analysis}

The probability of survival was estimated using the Kaplan-Meier method and compared using the log-rank test. The multivariate Cox proportional hazards model was used to estimate hazard ratios (HRs) and 95\% confidence intervals (CIs) for the chance of survival. Age, sex, stage of primary tumor, histology, recurrence site, interval between surgery and recurrence, biological effective dose (BED) of radiation, concurrent chemotherapy, EGFR status, irradiation technique, and GTV were included in univariate analysis. All tests were two-sided. Univariate variables that reached a $P$ value $<0.2$ were evaluated in multivariate analysis. $P$ values less than 0.05 were considered significant. All statistical analyses were performed using SPSS 22.0 software (IBM, Chicago, IL, USA).

\section{Results}

\section{Patient characteristics}

We identified 74 patients comprising 20 females and 54 males. The median age of patients was 59 years (range 29-84 years). Patient characteristics are summarized in Table 1. The information of pathologic stage of tumor confirmed after initial surgery was available for 67 patients, 34 of whom had stage III disease. Information of EGFR status was available for 51 patients, of which 14 had EGFR mutation. The median interval between surgery and recurrence was 11 months (range 6-104 months). Regional lymph nodes were the most common site for recurrence [56 cases $(75.7 \%)$ ].

Most patients underwent IMRT. The median GTV was $28.7 \mathrm{~cm}^{3}$ (range $2.6-189.3 \mathrm{~cm}^{3}$ ). The median BED of radiation was 78 Gy (range 55-119 Gy). Fifty-nine (79.7\%) patients underwent concurrent chemotherapy: $52(70.3 \%)$ were treated with platinum-based dual drugs, and $7(9.4 \%)$ underwent single-agent treatment. Eighteen (24.3\%) patients underwent neoadjuvant chemotherapy for recurrent disease before radiotherapy.

\section{Adverse events}

The average weight loss was $0.8 \mathrm{~kg}$ (range $0-6.5 \mathrm{~kg}$ ). The most frequent adverse events observed were neutropenia, esophagitis, pneumonitis, and vomiting, and most were mild (grades 1 and 2). Grade 3 neutropenia occurred in $8(10.8 \%)$ patients, followed by grade $3 / 4$ esophagitis in $7(9.5 \%)$ patients, grade 3 pneumonitis in $1(1.4 \%)$ patient, and grade 3 vomiting in 1 (1.4\%) patient. Grade 4 esophagitis occurred in 1 (1.4\%) patient, who developed malignant fistulae. There were no treatmentrelated deaths.

\section{Treatment outcome}

Two months after radical radiotherapy, 11 (14.9\%) patients achieved CR, 36 (48.6\%) achieved PR, 14 (18.9\%) had SD, and 13 (17.6\%) had PD. With a median follow-up of 21.5 months (range 2-50 months), the 2-year OS, PFS, LRFS, and DMFS rates of all patients were 84.2, 42.5, 70.0 , and $50.9 \%$, respectively. Sixteen patients died during follow-up. The median estimated OS was not reached. The median estimated PFS, LRFS, and DMFS were 19.0, 40.4, and 24.8 months, respectively (Fig. 1 ).

Univariate and multivariate analyses showed that higher BED of radiation was associated with longer 
Table 1 Characteristics of 74 NSCLC patients with postoperative locoregional recurrence treated with radical radiotherapy

\begin{tabular}{|c|c|}
\hline Characteristic & Number of patients (\%) \\
\hline \multicolumn{2}{|l|}{ Sex } \\
\hline Male & $54(73.0)$ \\
\hline Female & $20(27.0)$ \\
\hline \multicolumn{2}{|l|}{ Stage of primary tumor ${ }^{\mathrm{a}}$} \\
\hline 1 & $17(23.0)$ \\
\hline$\|$ & $16(21.6)$ \\
\hline III & $34(45.9)$ \\
\hline Unknown & $7(9.5)$ \\
\hline \multicolumn{2}{|l|}{ Histology } \\
\hline Squamous cell carcinoma & $18(24.3)$ \\
\hline Adenocarcinoma & $41(55.4)$ \\
\hline Lymphoepithelioma-like carcinoma & $10(13.3)$ \\
\hline Others & $5(6.8)$ \\
\hline \multicolumn{2}{|l|}{ EGFR status } \\
\hline Mutation & $14(18.9)$ \\
\hline Wild-type & $37(50.0)$ \\
\hline Unknown & $23(31.1)$ \\
\hline \multicolumn{2}{|l|}{ Recurrence site } \\
\hline Stump & $8(10.8)$ \\
\hline Regional lymph nodes & $56(75.7)$ \\
\hline Ipsilateral lung & $6(8.1)$ \\
\hline Both stump and regional lymph nodes & $3(4.0)$ \\
\hline $\begin{array}{l}\text { Both regional lymph nodes and ipsilateral } \\
\text { lung }\end{array}$ & $1(1.4)$ \\
\hline \multicolumn{2}{|l|}{ Concurrent chemotherapy } \\
\hline Yes & $59(79.7)$ \\
\hline No & $15(20.3)$ \\
\hline \multicolumn{2}{|l|}{ Radiation technique } \\
\hline 3D-CRT & $5(6.8)$ \\
\hline IMRT & $62(83.8)$ \\
\hline SBRT & $7(9.4)$ \\
\hline
\end{tabular}

NSCLC non-small cell lung cancer, EGFR epidermal growth factor receptor, 3D-CRT 3-dimensional conformal radiotherapy, IMRT intensity-modulated radiotherapy, SBRT stereotactic body radiotherapy

a The 7th edition of the American Joint Committee on Cancer (AJCC) staging system was used

LRFS (HR $=0.317,95 \% \mathrm{CI}=0.112-0.899, P=0.016)$ and that the presence of wild-type EGFR was associated with longer DMFS compared with EGFR mutations $(\mathrm{HR}=0.383,95 \% \mathrm{CI}=0.171-0.855, P=0.019)$ (Tables 2 , 3).

\section{Failure pattern}

During follow-up, 35 (47.3\%) patients experienced disease progression. The most common failure pattern was locoregional recurrence plus distant metastasis, observed in $16(21.6 \%)$ patients. Fifteen $(20.3 \%)$ patients had distant metastasis alone, and $4(5.4 \%)$ had locoregional recurrence alone. The contralateral lung (14 cases, 18.9\%) was the most common site of metastasis, followed by the brain ( 5 cases, $6.8 \%$ ), liver ( 4 cases, $5.4 \%$ ), bone ( 3 cases, $4.1 \%$ ), adrenal gland (2 cases, $2.7 \%$ ), celiac lymph nodes ( 2 cases, $2.7 \%$ ), and axillary lymph nodes (1 case, 1.4\%). Among the 20 patients with locoregional progression, 7 (35.0\%) had progression at the previous recurrence sites.

\section{Discussion}

The present study demonstrated that radical radiotherapy was effective and well-tolerated in NSCLC patients with postoperative locoregional recurrence. The 2-year OS, PFS, LRFS, and DMFS rates of all patients were $84.2,42.5$, 70.0 , and $50.9 \%$, respectively. We evaluated the possible prognostic roles of age, sex, interval between surgery and recurrence, BED of radiation, concurrent chemotherapy, EGFR status, and GTV. High BED appeared to be an independent predictor for prolonged LRFS. Patients with wild-type $E G F R$ were found to have longer DMFS than those with EGFR mutation.

No independent predictors for OS were identified in the present study. In univariate analysis, BED showed a trend to be associated with OS $(P=0.053)$. However, the difference was not significant in multivariate analysis $(P=0.472)$. The prognostic factors for OS of patients with local recurrence were also investigated in several retrospective studies. Female [7, 18], young age [7], long disease-free interval between initial surgery and local recurrence $[7,15]$, and high radiation dose prescribed [16] were reported to be associated with prolonged OS. Early stage of primary tumor [18] and recurrent lesion $[15,18]$ as well as recurrence in the bronchial stump $[16$, $18-20]$ were also reported to be associated with prolonged OS.

Several studies have demonstrated that BED of radiation was associated with local control in NSCLC patients receiving radiotherapy [21-23]. After analyzing potential prognostic factors, we found that higher BED was an independent indicator for longer LRFS $(P=0.031)$ in the present study. Patients receiving a BED of radiation no less than 78 Gy had a longer LRFS than did those receiving a BED less than 78 Gy. Therefore, escalating BED might be helpful to patients with local recurrence. However, the volume of the lungs of NSCLC patients was decreased with reduced pulmonary function after surgery. Some patients had received several cycles of adjuvant or neoadjuvant chemotherapy, which resulted in poor performance status. Therefore, the lung toxicity accompanied with high BED warrants attention, and the dose constraints for normal tissues should be followed strictly. In the present study, a mean lung dose less than $17 \mathrm{~Gy}$ and the lung volumes irradiated above $20 \mathrm{~Gy}\left(\mathrm{~V}_{20}\right)$ less than $30 \%$ were constrained. Only 1 patient had grade 
3 pneumonitis. No grade 4/5 lung adverse event was found.

As we know, concurrent chemotherapy prolonged survival of patients with unresectable stage III NSCLC [2429]. For patients with postoperative local recurrence, the role of concurrent chemotherapy has not been fully elucidated $[14,30]$. Our results did not support the prognostic role of chemotherapy for survival. However, this result must be interpreted with caution. Among the 14 patients who did not receive concurrent chemotherapy, 5 were treated with SBRT. The high BED of SBRT could achieve good local control in the absence of concurrent chemotherapy. Therefore, the inclusion of patients receiving SBRT might dilute the role of chemotherapy in the entire cohort. Moreover, our data showed that the major failure pattern after radical radiotherapy was distant metastasis, consistent with the results reported by Kelsey et al. [15], which revealed that $50 \%$ patients developed distant metastases after salvage radiotherapy. The high rate of distant metastasis after radical radiotherapy indicates that chemotherapy is important for NSCLC patients with locoregional recurrence. Therefore, the value of chemotherapy concurrent with or after radiotherapy is worthy of further exploration.

Data from multiple randomized trials have demonstrated that EGFR mutation may be used as a predictive factor for tumor response to tyrosine kinase inhibitors (TKIs) and biomarkers for TKI treatment selection [31-33]. NSCLC patients with postoperative locoregional recurrence who harbored EGFR gene mutations were also reported to benefit from TKIs [34]. In the present study, our results showed that EGFR-mutated NSCLC patients were more likely to have distant failure after radical radiotherapy as compared with those with wild-type $\operatorname{EGFR}(P=0.019)$. Our previous study investigated the association of EGFR mutation status with treatment outcome of patients with stage III NSCLC

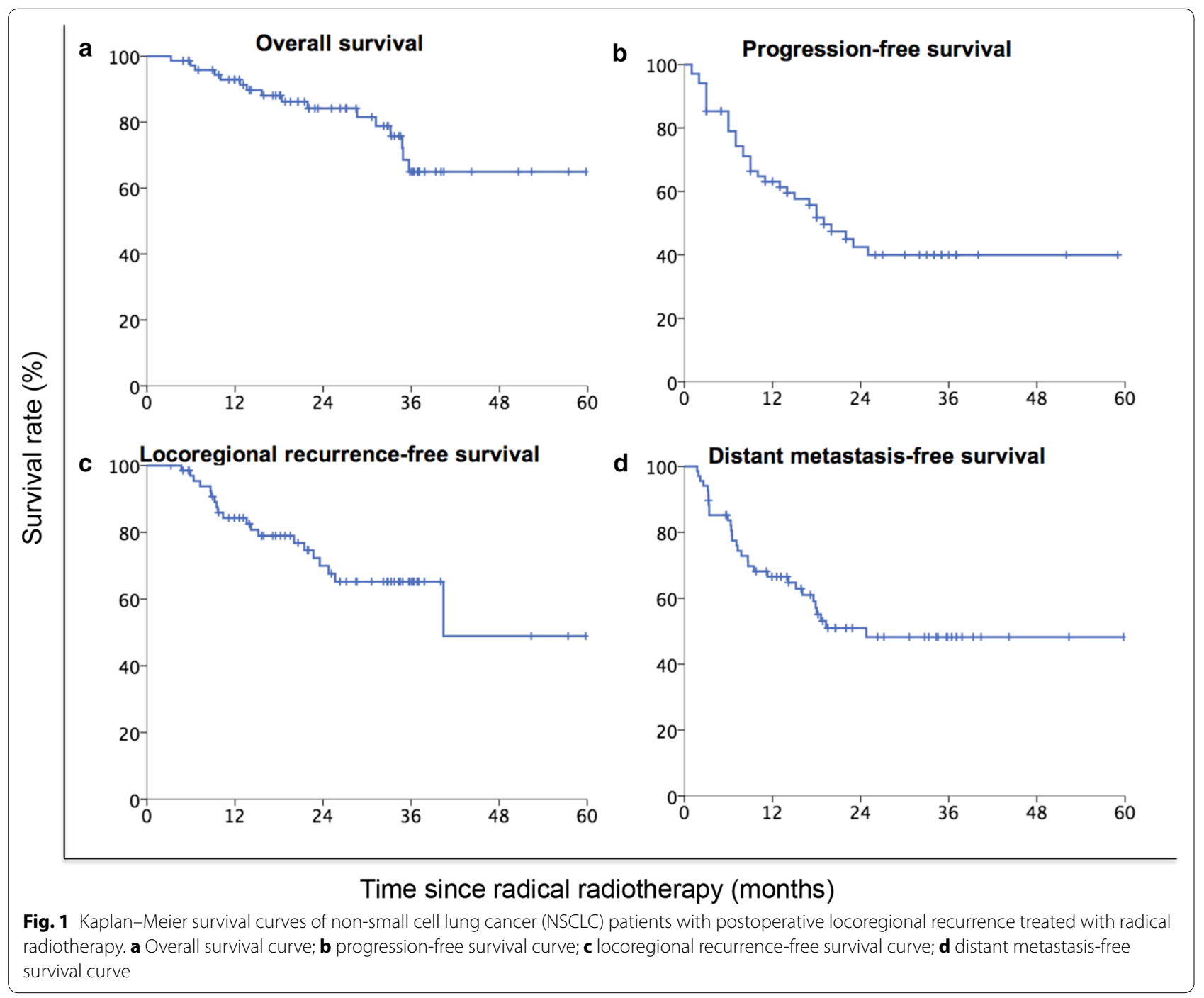


Table 2 Univariate analyses of prognostic factors for 74 NSCLC patients with postoperative locoregional recurrence treated with radical radiotherapy

\begin{tabular}{|c|c|c|c|c|c|c|c|c|}
\hline \multirow[t]{2}{*}{ Variable } & \multicolumn{2}{|l|}{ OS } & \multicolumn{2}{|l|}{ PFS } & \multicolumn{2}{|l|}{ LRFS } & \multicolumn{2}{|l|}{ DMFS } \\
\hline & $\mathrm{HR}(95 \% \mathrm{Cl})$ & $P$ value & $\mathrm{HR}(95 \% \mathrm{Cl})$ & $P$ value & $\mathrm{HR}(95 \% \mathrm{Cl})$ & $P$ value & $\mathrm{HR}(95 \% \mathrm{Cl})$ & $P$ value \\
\hline Age ( $\geq 59$ vs. $<59$ years) & $1.387(0.517-3.723)$ & 0.516 & $0.532(0.264-1.071)$ & 0.077 & $0.789(0.322-1.932)$ & 0.604 & $0.619(0.296-1.292)$ & 0.201 \\
\hline Sex (male vs. female) & $0.694(0.197-2.443)$ & 0.570 & $1.234(0.603-2.527)$ & 0.565 & $0.898(0.324-2.492)$ & 0.837 & $1.286(0.605-2.735)$ & 0.513 \\
\hline $\begin{array}{l}\text { Stage of primary tumor (I } \\
\text { vs. II vs. III) }\end{array}$ & $1.308(0.700-2.447)$ & 0.400 & $1.173(0.775-1.775)$ & 0.451 & $1.084(0.643-1.827)$ & 0.762 & $1.189(0.758-1.863)$ & 0.451 \\
\hline $\begin{array}{l}\text { Histology (squamous cell } \\
\text { carcinoma vs. non-squa- } \\
\text { mous cell carcinoma) }\end{array}$ & $0.755(0.261-2.183)$ & 0.604 & $1.125(0.510-2.482)$ & 0.770 & $0.750(0.270-2.085)$ & 0.582 & $1.420(0.582-3.466)$ & 0.441 \\
\hline $\begin{array}{l}\text { Recurrence site (stump vs. } \\
\text { regional lymph nodes } \\
\text { vs. ipsilateral lung vs. } \\
\text { multiple sites) }\end{array}$ & $1.292(0.689-2.423)$ & 0.425 & $1.284(0.767-2.149)$ & 0.342 & $1.439(0.780-2.655)$ & 0.245 & $1.433(0.840-2.445)$ & 0.187 \\
\hline $\begin{array}{l}\text { Interval between surgery } \\
\text { and recurrence ( } \geq 10 \text { vs. } \\
<10 \text { months) }\end{array}$ & $0.882(0.328-2.373)$ & 0.803 & $0.690(0.352-1.351)$ & 0.279 & $1.054(0.434-2.559)$ & 0.908 & $0.655(0.320-1.339)$ & 0.246 \\
\hline $\begin{array}{l}\text { BED of radiation ( } \geq 78 \text { vs. } \\
<78 \text { Gy) }\end{array}$ & $0.347(0.119-1.013)$ & 0.053 & $0.905(0.466-1.758)$ & 0.769 & $0.288(0.104-0.795)$ & 0.016 & $1.075(0.531-2.175)$ & 0.841 \\
\hline $\begin{array}{l}\text { Concurrent chemotherapy } \\
\text { (yes vs. no) }\end{array}$ & $1.222(0.348-4.294)$ & 0.754 & $1.114(0.485-2.555)$ & 0.799 & $1.247(0.412-3.774)$ & 0.696 & $1.150(0.471-2.808)$ & 0.758 \\
\hline $\begin{array}{l}\text { EGFR status (wild-type } \\
\text { vs. mutation type vs. } \\
\text { unknown) }\end{array}$ & $0.265(0.063-1.112)$ & 0.069 & $0.509(0.238-1.088)$ & 0.509 & $1.694(0.465-6.175)$ & 0.425 & $0.418(0.192-0.912)$ & 0.028 \\
\hline $\begin{array}{l}\text { Radiation technique (3D- } \\
\text { CRT vs. IMRT vs. SBRT) }\end{array}$ & $2.562(0.887-7.395)$ & 0.082 & $1.213(0.554-2.654)$ & 0.630 & $2.047(0.757-5.537)$ & 0.158 & $1.130(0.472-2.701)$ & 0.784 \\
\hline GTV $\left(\geq 28.7\right.$ vs. $\left.<28.7 \mathrm{~cm}^{3}\right)$ & $1.864(0.637-5.455)$ & 0.256 & $1.246(0.593-2.617)$ & 0.561 & $0.543(0.201-1.470)$ & 0.230 & $1.525(0.682-3.411)$ & 0.304 \\
\hline
\end{tabular}

OS overall survival, PFS progression-free survival, LRFS local recurrence-free survival, DMFS distant metastasis-free survival, $H R$ hazard ratio, $C I$ confidence interval, $B E D$ biological effective dose, EGFR epidermal growth factor receptor, 3D-CRT 3-dimensional conformal radiotherapy, IMRT intensity-modulated radiotherapy, SBRT stereotactic body radiotherapy, GTV gross tumor volume

Table 3 Multivariate analyses of prognostic factors for 74 NSCLC patients with postoperative locoregional recurrence treated by radical radiotherapy

\begin{tabular}{|c|c|c|c|c|c|c|c|c|}
\hline \multirow[t]{2}{*}{ Variable } & \multicolumn{2}{|l|}{ OS } & \multicolumn{2}{|l|}{ PFS } & \multicolumn{2}{|l|}{ LRFS } & \multicolumn{2}{|l|}{ DMFS } \\
\hline & $\mathrm{HR}(95 \% \mathrm{Cl})$ & $P$ value & $\mathrm{HR}(95 \% \mathrm{CI})$ & $P$ value & $\mathrm{HR}(95 \% \mathrm{Cl})$ & $P$ value & $\mathrm{HR}(95 \% \mathrm{Cl})$ & $P$ value \\
\hline $\begin{array}{l}\text { Recurrence site (stump vs. } \\
\text { regional lymph nodes vs. ipsi- } \\
\text { lateral lung vs. multiple sites) }\end{array}$ & - & & - & & - & & $1.421(0.802-2.519)$ & 0.229 \\
\hline $\begin{array}{l}\text { BED of radiation ( } \geq 78 \mathrm{vs} \text {. } \\
\quad<78 \mathrm{~Gy} \text { ) }\end{array}$ & $0.472(0.070-3.182)$ & 0.472 & - & & $0.317(0.112-0.899)$ & 0.031 & - & \\
\hline $\begin{array}{l}\text { EGFR status (wild-type vs. muta- } \\
\text { tion type vs. unknown) }\end{array}$ & $0.227(0.034-1.498)$ & 0.118 & - & & - & & $0.383(0.171-0.855)$ & 0.019 \\
\hline $\begin{array}{l}\text { Radiation technique (3D-CRT vs. } \\
\text { IMRT vs. SBRT) }\end{array}$ & $4.406(0.667-29.085)$ & 0.124 & - & & $1.525(0.516-4.503)$ & 0.445 & - & \\
\hline
\end{tabular}

OS overall survival, PFS progression free survival, LRFS local recurrence free survival, DMFS distant metastasis free survival, $H R$ hazard ratio, $C$ I confidence interval, $B E D$ biological effective dose, EGFR epidermal growth factor receptor, 3D-CRT 3-dimensional conformal radiotherapy, IMRT intensity-modulated radiotherapy, SBRT stereotactic body radiotherapy, GTV gross tumor volume, - not included

who had undergone a complete (R0) resection, and found that patients with mutant EGFR had a higher rate of multiple distant metastases after surgery than those with wildtype EGFR [35]. However, EGFR mutation status was not found to be a prognostic factor for OS in either our previous study or the present study. The reason may be that
EGFR-mutated patients benefited from subsequent TKI treatment after distant failure. EGFR mutation seems to be more like a predictive marker for TKI treatment than a prognostic marker for OS.

The safety of radiotherapy for NSCLC patients with postoperative locoregional recurrence has been 
demonstrated by other researchers [12-14, 16]. Similarly, the toxicities were acceptable in the present study. Grade 3 adverse events including pneumonitis, neutropenia, vomiting, and esophagitis appeared in 16 patients. Only one developed grade 4 radiation-related esophagitis (esophagus fistula).

Our results demonstrated that NSCLC patients with postoperative locoregional recurrence could benefit from radical radiotherapy. However, this study had several limitations, such as the short follow-up, small sample size, and a retrospective nature. The results should be confirmed in larger prospective studies.

\section{Conclusions}

Radical radiotherapy is effective and well-tolerated in NSCLC patients with postoperative locoregional recurrence. High BED of radiation appeared to be an independent favorable factor for LRFS. Patients with wild-type EGFR were found to have longer DMFS than those with EGFR mutations. Distant failure accounted for the substantial treatment failure after radical radiotherapy. The values of chemotherapy concurrent with or after radiotherapy should be further explored.

\section{Authors' contributions}

$H L, S P G$, and BQ performed the conception and design of the study. $L M$, QWL, JZ, ZLC, XHZ, and MYQ performed acquisition of data. LM, BQ, and BW analyzed data. $\mathrm{LM}, \mathrm{QWL}$, and $\mathrm{BQ}$ drafted the article and revised it critically for important intellectual content. HL and SPG made the final approval of the version to be submitted. All authors read and approved the final manuscript.

\section{Acknowledgements}

This work was supported by the Science and Technology Planning Project of Guangdong Province, China (No. 2016A020215190, 2016ZC0030); the Scientific Research Foundation for the Returned Overseas Chinese Scholars, State Education Ministry; and the National Natural Science Foundation of China (No. 81301932).

\section{Competing interests}

The authors declare that they have no competing interests.

\section{Ethics approval and consent to participate}

Participant information collection was approved by the Ethics Committee of Sun Yat-sen University Cancer Center. Written informed consent was obtained from the patient for the publication of this report and any accompanying images.

\section{Availability of data and materials}

The key raw data have been deposited into the Research Data Deposit (http:// www.researchdata.org.cn), with the approval number of RDDA2017000218.

Received: 19 January 2017 Accepted: 27 June 2017

Published online: 11 December 2017

\section{References}

1. Ferlay J, Soerjomataram I, Dikshit R, Eser S, Mathers C, Rebelo M, et al. Cancer incidence and mortality worldwide: sources, methods and major patterns in GLOBOCAN 2012. Int J Cancer. 2015;136(5):E359-86.

2. Goldstraw P, Crowley J, Chansky K, Giroux DJ, Groome PA, Rami-Porta $R$, et al. The IASLC lung cancer staging project: proposals for the revision of the TNM stage groupings in the forthcoming (seventh) edition of the TNM classification of malignant tumours. J Thorac Oncol. 2007:2(8):706-14.

3. Yang HX. Long-term survival of early-stage non-small cell lung cancer patients who underwent robotic procedure: a propensity score-matched study. Chin J Cancer. 2016;35(1):66.

4. Endo C, Sakurada A, Notsuda H, Noda M, Hoshikawa Y, Okada Y, et al. Results of long-term follow-up of patients with completely resected nonsmall cell lung cancer. Ann Thorac Surg. 2012;93(4):1061-8.

5. Kelsey CR, Marks LB, Hollis D, Hubbs JL, Ready NE, D'Amico TA, et al. Local recurrence after surgery for early stage lung cancer: an 11-year experience with 975 patients. Cancer. 2009;115(22):5218-27.

6. Sugimura H, Nichols FC, Yang P, Allen MS, Cassivi SD, Deschamps C, et al. Survival after recurrent nonsmall-cell lung cancer after complete pulmonary resection. Ann Thorac Surg. 2007;83(2):409-17 (discussion 417-408)

7. Yano T, Hara N, Ichinose $Y$, Asoh H, Yokoyama H, Ohta M, et al. Local recurrence after complete resection for non-small-cell carcinoma of the lung. Significance of local control by radiation treatment. J Thorac Cardiovasc Surg. 1994;107(1):8-12.

8. Yano T, Okamoto T, Fukuyama S, Maehara Y. Therapeutic strategy for postoperative recurrence in patients with non-small cell lung cancer. World J Clin Oncol. 2014;5(5):1048-54.

9. Dautzenberg B, Arriagada R, Chammard AB, Jarema A, Mezzetti M, Mattson $\mathrm{K}$, et al. A controlled study of postoperative radiotherapy for patients with completely resected nonsmall cell lung carcinoma. Groupe d'etude et de traitement des cancers bronchiques. Cancer. 1999;86(2):265-73.

10. Rosell R, Gomez-Codina J, Camps C, Maestre J, Padille J, Canto A, et al. A randomized trial comparing preoperative chemotherapy plus surgery with surgery alone in patients with non-small-cell lung cancer. N Engl J Med. 1994;330(3):153-8.

11. Williams BA, Sugimura H, Endo C, Nichols FC, Cassivi SD, Allen MS, et al. Predicting postrecurrence survival among completely resected nonsmallcell lung cancer patients. Ann Thorac Surg. 2006;81(3):1021-7.

12. Palma DA, Senan S, Oberije C, Belderbos J, de Dios NR, Bradley JD, et al. Predicting esophagitis after chemoradiation therapy for non-small cell lung cancer: an individual patient data meta-analysis. Int J Radiat Oncol Biol Phys. 2013;87(4):690-6.

13. Okami J, Nishiyama K, Fujiwara A, Konishi K, Kanou T, Tokunaga T, et al. Radiotherapy for postoperative thoracic lymph node recurrence of non-smallcell lung cancer provides better outcomes if the disease is asymptomatic and a single-station involvement. J Thorac Oncol. 2013:8(11):1417-24.

14. Takenaka T, Takenoyama M, Toyozawa R, Inamasu E, Yoshida T, Toyokawa $\mathrm{G}$, et al. Concurrent chemoradiotherapy for patients with postoperative recurrence of surgically resected non-small-cell lung cancer. Clin Lung Cancer. 2015:16(1):51-6.

15. Kelsey CR, Clough RW, Marks LB. Local recurrence following initial resection of NSCLC: salvage is possible with radiation therapy. Cancer J. 2006;12(4):283-8.

16. Kagami $Y$, Nishio $M$, Narimatsu $N$, Mjoujin M, Sakurai T, Hareyama M, et al. Radiotherapy for locoregional recurrent tumors after resection of nonsmall cell lung cancer. Lung Cancer. 1998;20(1):31-5.

17. Liang J, Bi N, Wu S, Chen M, Lv C, Zhao L, et al. Etoposide and cisplatin versus paclitaxel and carboplatin with concurrent thoracic radiotherapy in unresectable stage III non-small cell lung cancer: a multicenter randomized phase III trial. Ann Oncol. 2017;28(4):777-83.

18. Jeremic B, Shibamoto Y, Milicic B, Milisavljevic S, Nikolic N, Dagovic A, et al. External beam radiation therapy alone for loco-regional recurrence of non-small-cell lung cancer after complete resection. Lung Cancer. 1999:23(2):135-42.

19. Curran WJ Jr, Herbert SH, Stafford PM, Sandler HM, Rosenthal SA, McKenna WG, et al. Should patients with post-resection locoregional recurrence of lung cancer receive aggressive therapy? Int J Radiat Oncol Biol Phys. 1992;24(1):25-30

20. Leung J, Ball D, Worotniuk T, Laidlaw C. Survival following radiotherapy for post-surgical locoregional recurrence of non-small cell lung cancer. Lung Cancer. 1995;13(2):121-7.

21. Grills IS, Hope AJ, Guckenberger M, Kestin LL, Werner-Wasik M, Yan D, et al. A collaborative analysis of stereotactic lung radiotherapy outcomes for early-stage non-small-cell lung cancer using daily online cone-beam 
computed tomography image-guided radiotherapy. J Thorac Oncol. 2012;7(9):1382-93.

22. Chang JY, Roth JA. Stereotactic body radiation therapy for stage I nonsmall cell lung cancer. Thorac Surg Clin. 2007;17(2):251-9.

23. Machtay M, Bae K, Movsas B, Paulus R, Gore EM, Komaki R, et al. Higher biologically effective dose of radiotherapy is associated with improved outcomes for locally advanced non-small cell lung carcinoma treated with chemoradiation: an analysis of the radiation therapy oncology group. Int J Radiat Oncol Biol Phys. 2012;82(1):425-34.

24. Akhtari M, Bernicker EH, Teh BS. Chemotherapy in non-small cell lung cancer: opportunities for advancement. Chin J Cancer. 2016:35(1):56.

25. Auperin A, Le Pechoux C, Rolland E, Curran WJ, Furuse K, Fournel P, et al. Meta-analysis of concomitant versus sequential radiochemotherapy in locally advanced non-small-cell lung cancer. J Clin Oncol. 2010;28(13):2181-90.

26. Furuse K, Fukuoka M, Kawahara M, Nishikawa H, Takada Y, Kudoh S, et al. Phase III study of concurrent versus sequential thoracic radiotherapy in combination with mitomycin, vindesine, and cisplatin in unresectable stage III non-small-cell lung cancer. J Clin Oncol. 1999;17(9):2692-9.

27. Curran WJ Jr, Paulus R, Langer CJ, Komaki R, Lee JS, Hauser S, et al. Sequential vs. concurrent chemoradiation for stage III non-small cell lung cancer: randomized phase III trial RTOG 9410. J Natl Cancer Inst. 2011;103(19):1452-60.

28. Ulutin HC, Guden M, Oysul K, Surenkok S, Pak Y. Split-course radiotherapy with or without concurrent or sequential chemotherapy in non-small cell lung cancer. Radiat Med. 2000;18(2):93-6.
29. Belderbos J, Uitterhoeve L, van Zandwijk N, Belderbos H, Rodrigus P, van de Vaart $P$, et al. Randomised trial of sequential versus concurrent chemoradiotherapy in patients with inoperable non-small cell lung cancer (EORTC 08972-22973). Eur J Cancer. 2007:43(1):114-21.

30. Bar J, Ng D, Moretto P, Goss GD, Sun A, Macrae R, et al. Chemoradiotherapy for locoregional recurrence of non-small-cell lung cancer after surgical resection: a retrospective analysis. Clin Lung Cancer. 2013;14(2):200-4.

31. Dahabreh IJ, Linardou H, Siannis F, Kosmidis P, Bafaloukos D, Murray S. Somatic EGFR mutation and gene copy gain as predictive biomarkers for response to tyrosine kinase inhibitors in non-small cell lung cancer. Clin Cancer Res. 2010;16(1):291-303.

32. Han SW, Kim TY, Hwang PG, Jeong S, Kim J, Choi IS, et al. Predictive and prognostic impact of epidermal growth factor receptor mutation in non-small-cell lung cancer patients treated with gefitinib. J Clin Oncol. 2005;23(11):2493-501.

33. Delaney C, Frank S, Huang RS. Pharmacogenomics of EGFR-targeted therapies in non-small cell lung cancer: EGFR and beyond. Chin J Cancer. 2015:34(4):149-60.

34. Takenaka T, Takenoyama M, Yamaguchi M, Toyozawa R, Inamasu E, Kojo $\mathrm{M}$, et al. Impact of the epidermal growth factor receptor mutation status on the post-recurrence survival of patients with surgically resected nonsmall-cell lung cancer. Eur J Cardiothorac Surg. 2015;47(3):550-5.

35. Liu SR, Qiu B, Yang H, Liang Y, Wang F, Liu SL, et al. Epidermal growth factor receptor mutation status and treatment outcome for R0-resected patients with stage 3 non-small cell lung cancer. Ann Surg Oncol. 2016;23(6):2115-22.

\section{Submit your next manuscript to BioMed Central and we will help you at every step:}

- We accept pre-submission inquiries

- Our selector tool helps you to find the most relevant journal

- We provide round the clock customer support

- Convenient online submission

- Thorough peer review

- Inclusion in PubMed and all major indexing services

- Maximum visibility for your research

Submit your manuscript at www.biomedcentral.com/submit 